\title{
Poll Everywhere E-Learning Platform, Test Anxiety, and Undergraduates' Academic Performance in Mathematics: Empirical Evidence from Nigeria
}

American Journal of Social Sciences and Humanities

Vol. 5, No. 1, 141-150, 2020

e-ISSN: 2520-5382

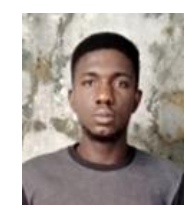

(20) Corresponding Author)

\author{
iD Valentine Joseph Owan ${ }^{10}$ \\ Bassey Asuquo Bassey ${ }^{2}$ \\ Garieth Omorobi Omorobi ${ }^{3}$ \\ Uwase Uwase Esuong ${ }^{4}$
}

\author{
${ }^{1,3}$ Department of Educational Management, University of Calabar, Calabar, Nigeria. \\ Email:owanvalentine@gmail.com Tel:+234706291462s \\ Email:omobitchrist@gmail.com Tel: +2347060624691 \\ -Department of Educational Foundations, University of Calabar, Calabar, Nigeria. \\ Email:babssey67@gmail.com Tel: +2s480354076s9 \\ ${ }^{*}$ Mathematics Unit, Department of Science Education University of Calabar, Nigeria. \\ Email urvaseesuong@agmail.com Tel: +2348063274768
}

\section{ABSTRACT}

The high rate of mathematics education students' academic performance in universities has become unbearable. In an attempt to proffer solution to this menace, this study assessed Poll Everywhere eLearning platform, test anxiety, and undergraduates' academic performance in Mathematics in Cross River State, Nigeria. The study adopted a quasi-experimental research one control group and one treatment group. The population of this study comprised all the fulltime regular undergraduates offering Education Mathematics in the Department of Science Education, University of Calabar, Calabar, Nigeria. Accidental sampling technique was adopted in selecting a sample of 328 undergraduates who are owners of smartphones from the population. Test-Anxiety Inventory and Mathematics Achievement Test (MAT) were used as data collection instruments. The null hypotheses were tested using independent t-tests and simple linear regression. Findings revealed that Poll Everywhere eLearning platform has a significant effect on students' test anxiety and academic performance in Mathematics respectively; there is a moderate negative and significant relationship between students' test anxiety and their academic performance in Mathematics. Based on the findings of this study, it was concluded that Poll Everywhere eLearning platform could be used for the effective teaching and examination of learners in Mathematics and other science-related disciplines. This can be done through the design and integration of course modules to the Poll Everywhere online platform.

Keywords: Poll everywhere, E-learning, Test anxiety, Undergraduates, Academic performance, Mathematics.

DOI: $10.20448 / 801.51 .141 .150$

Citation | Valentine Joseph Owan; Bassey Asuquo Bassey; Garieth Omorobi Omorobi; Uwase Uwase Esuong (2020). Poll Everywhere E-Learning Platform, Test Anxiety, and Undergraduates' Academic Performance in Mathematics: Empirical Evidence from Nigeria. American Journal of Social Sciences and Humanities, 5(1): 141-150.

Copyright: This work is licensed under a Creative Commons Attribution 3.0 License

Funding: This study received no specific financial support.

Competing Interests: The authors declare that they have no competing interests.

History: Received: 7 October 2019/ Revised: 12 November 2019/ Accepted: 16 December 2019/ Published: 31 January 2020 Publisher: Online Science Publishing 


\section{Highlights of this paper}

- This study was undertaken as a response to the abysmal academic performance of undergraduates in mathematics. In this study, Poll Everywhere eLearning platform, test anxiety, and undergraduates' academic performance in Mathematics was assessed.

- It was discovered that Poll Everywhere E-learning platform has a significant effect on students' test anxiety. Test anxiety was lower among students that were taught using the Poll Everywhere eLearning than those taught using the traditional approach.

- It was also indicated that Poll Everywhere eLearning platform has a significant effect on students' academic performance in Mathematics. Students taught using the Poll Everywhere Elearning platform performed higher in Mathematics than those in the control group.

- There is a moderate negative and significant relationship between students' test anxiety and their academic performance in Mathematics.

\section{INTRODUCTION}

Mathematics is one of the most important subjects in science education because it takes into consideration, the day-to-day activities of households and in keeping numerical facts about events, financial records, and other transactions involving numbers or numeration. Based on the importance of this subject matter, individuals studying such a course at the secondary or tertiary level were expected to show commitment and be studious to boost their academic performance and enjoy other benefits attached to the study of Mathematics. The academic performance of undergraduates in Mathematics in recent times have witnessed a dramatic rise in the negative direction. Keen observation has proven that many undergraduates studying Mathematics Education are also not different from their counterparts in Mathematics Major.

In time past, undergraduates do complain about the complexities bordering around Mathematics courses involving complex computations and/or statistics, which affects their performance in the discipline. This reason has, however, been taken lightly since the performance of students in other Mathematics courses not involving complex formulas has not been different. This suggested to the researchers that the issue of poor academic performance by Mathematics students is generally dwindling across all courses. Several studies have been attracted to address similar problems with several recommendations made at different times and places (Adu et al., 2012; Ganyaupfu, 2013; Effiom and Bassey, 2018; Bassey et al., 2019; Owan and Ekaette, 2019).

Several factors have been outlined in the literature by scholars and researchers as correlates of students academic performance. Such factors include: problems of school management (Owan et al., 2018), school leadership behaviour (Tatlah et al., 2014) students' disability status (Lagoke et al., 2010) students' perception of discipline (Offem et al., 2019) teacher demographics representation (Holt and Gershenson, 2015) the management and utilization of social media (Arop et al., 2019; Owan and Robert, 2019).

Other studies outlined class attendance, age, learning styles or preferences, gender, class size, entry qualifications, family income, students' perception, poor discipline of students, students' attitudes, teachers qualification, the school physical environment, and the school leadership as factors affecting students performance (Haist et al., 2000; Aripin et al., 2008; Heinesen, 2010; Mlambo, 2011; Owan, 2012; Ali et al., 2013; Ehiane, 2014; Owan and Ekpe, 2019).

This study, however, takes a shift to consider students' test anxiety as a factor that may also be responsible for students' performance. This is because, while many students have little or no reasons for their unacceptable performance in Mathematics, some other students attributed their abysmal performance to be unconnected with their fear of Mathematics as a difficult course which makes them lose confidence while preparing for, or during examinations. Such loss of confidence could raise their level of anxiety in taking Mathematics examinations, and consequently, their academic performance may be affected. 
According to Owan et al. (2019) test anxiety is a psychological construct which depicts the emotional state of an individual before performing a task. Test anxiety of students may be borne out of fear or one's perception of a task to be performed (Owan et al., 2019). It follows from the assertion above that test anxiety is a strong, and worrisome feeling, students portray towards test-taking all around the world. Test anxiety can be an overwhelming problem for many college students because it may impair their performance and comfort in the long run (Hanem, 2016). Studies have shown that students test anxiety affects the academic performance of students (Owan, 2012; Shuaibu et al., 2017; Effiom and Bassey, 2018; Owan et al., 2019).

Bhatta et al. (2018) investigated the prevalence and correlates of test anxiety. Result of the study showed that $76.3 \%$ of the students were suffering from some level of test anxiety. The result further showed that private school students had significantly high-test anxiety as compared to government school students. Also, test anxiety did not differ significantly for sex, type of family, academic achievement motivation, self-efficacy, emotional intelligence, and adjustment.

The results of Hanem (2016) indicated that there is a highly statistically significant inverse correlation between total test anxiety and grade point average $(\mathrm{P}<.01)$. it was concluded that test anxiety has a significant and efficient impact on nursing students' performance. It was recommended that students with superior test anxiety must be recognized and treated to increase their academic attainment. Another study showed that there is a significant correlation $(\mathrm{r}=-0.23, \mathrm{p}=.000)$ between test anxiety and academic achievement among adolescents (Yousefi et al., $2010)$.

Owan et al. (2019) assessed the administration of punishment, students' test anxiety, and performance in mathematics in secondary schools of Cross River State. Findings revealed amongst others that administration of punishment has a significant influence on students' test anxiety and performance in mathematics $\sqsubset \mathrm{F}(6$, 5098)=24.149, $\mathrm{p}<.05$; Wilk's $\Lambda=0.945$, partial $\left.\eta^{2}=.028\right]$ on a joint basis; administration of punishment has a significant influence respectively on students' test anxiety $\mathrm{F}(3,2550)=22.697, \mathrm{p}<.0005$, partial $\eta^{2}=.026$ and performance in mathematics $\left[\mathrm{F}(3,2550)=23.090, \mathrm{p}<.0005\right.$, partial $\left.\eta^{2}=.026\right]$; there is an inverse significant relationship ( $\mathrm{r}=-339, \mathrm{p}<0.05)$ between students' tests anxiety and performance in mathematics.

At the close of the $21^{\text {st }}$ century, several technological dynamics have been witnessed, with diverse e-learning platforms developed to help students learn more effectively. Such developments were based on the fact that elearning platforms provide a better opportunity for hands-on activities, removes the fear of facing teachers, eliminates the problems of shyness, as well as disciplinary problems, usually characterized by the traditional classroom. In the words of Coldwell et al. (2008).

Online learning environments (OLEs) facilitate learning by utilising software that enables the design, delivery, and management of online teaching and learning. The notion of providing courses wholly online is relatively new and allows students of diverse backgrounds and in geographically dispersed locations to have access to, and participate in, the same courses. In the past, students have been able to study 'off-campus', or from a distance, relying on study guides, detailed notes, and textbooks, but with few or no opportunities for interaction or collaboration. OLEs provide these resources but additionally, they enable regular interaction and collaboration between students and instructors through the use of discussion boards, chat rooms, and other interactive functionality, bringing all students into a 'virtual classroom'. The key difference between traditional off-campus and online is the ability for students to communicate and collaborate via the OLE, reducing the effects and limitations of isolation (p. 19). 
The importance of E-learning generally cannot be overstated, this study introduces a new E-learning platform known as "Poll Everywhere." Poll Everywhere is an online-based classroom and audience systems which can be used for the instruction and evaluation of learners just like in a typical classroom. This platform was founded in April 2007 by Sean Eby, Jeff Vyduna, Brad Gessler with its headquarters in San Francisco, California. This study generally, seems to be the first of its kind that assessed the effect of poll everywhere online platform on students test anxiety and academic performance in Mathematics. However, studies on e-learning show that it has a significant relationship with students' test anxiety (Alkhalaf et al., 2012; Bauk, 2015; Harandi, 2015).

Yazdi and Zandkarimi (2013) measured students' achievement motivation and test anxiety at the beginning and end of their educational term which was assigned for pre-test and post-test scores. The results represented that elearning in present site with teachers Teleworking and parent's virtual presence were more effective than the control group. It showed a reduction in the test anxiety and increased the achievement motivation and academic achievement scores among high school students. Studies on e-learning have also shown that it has a significant relationship with students' academic achievement. For instance, the findings of Zare et al. (2016) revealed that students in the experimental group demonstrated statistically significant higher scores on the measured variables, knowledge, and creativity. The study concluded that e-learning is effective for knowledge and creativity acquisitions among chemistry students and recommended that greater e-learning opportunities should be provided for wider audiences. Similarly, Tossy (2017) found that student confidence in e-learning systems have a positive significant relationship with students' achievement. Thabet and Kalyankar (2014) examined students' achievement between the two groups. The research results proved that there is a significant increase in gain in achievement, The EL has achieved efficiency greater than traditional learning in (Remembering, understanding, application) skills. Mutendwahothe (2013) explored the impact of e-Learning on the academic performance of student-teachers. Findings of the study provided evidence that e-Learning has a significant influence on the performance of students, as student-teachers taught using eLearning consistently performed better than student-teachers taught using the traditional method. Another study also showed that students' confidence in e-learning systems have a positive significant relationship with their achievement (Kisanjara et al., 2017). From the foregoing, it was deduced that different studies conducted world over, have made efforts to address the issue of students' academic performance while pairing it with several independent variables. Attempts on test anxiety and e-learning have also been made by scholars respectively. In particular, studies on e-learning failed to acknowledge the e-learning platforms used for experiments, hence, the focus has been on e-learning from the general perspective. The uniqueness of this study is that it intends to focus more specifically on "Poll Everywhere" e-learning platform to see the effect it has on students' test anxiety and academic performance in Mathematics while bridging the gaps on the paucity of research on e-learning in Cross River State, Nigeria.

\subsection{Purpose of the Study}

The specific purpose of this study is to assess:

i. The effect of Poll Everywhere E-learning platform on students' test anxiety.

ii. The effect of Poll Everywhere E-learning platform on students' academic performance in Mathematics.

iii. The relationship between students' test anxiety and their academic performance in Mathematics.

\subsection{Hypotheses}

The following null hypotheses were formulated to guide the study.

i. Poll Everywhere E-learning platform has no significant effect on students' test anxiety. 
ii. Poll Everywhere E-learning platform has no significant effect on students' academic performance in Mathematics.

iii. There is no significant relationship between students' test anxiety and their academic performance in Mathematics.

\section{METHODS}

This study adopted a quasi-experimental research one control group and one treatment group. The population of this study comprised all the fulltime regular undergraduates offering Mathematics Education in the Department of Science Education, University of Calabar, Calabar, Nigeria. This population comprised students that are owners of smartphones from year 1 to final year (year 4). These students were identified during their respective lectures according to grade level. Permission was obtained from the lecturer on duty and students who own smartphones were asked to raise their hands. In this way, it was easy to get their phone numbers for inclusion on a WhatsApp group designed for this study. Students who are owners of smartphones but that were not present in their classes were included through the snowball approach with the assistance of their colleagues. A total number of 328 students were eventually selected for the study. Two instruments - a Test-Anxiety Inventory (TAI) developed by Spielberger (1980) with 20 items. According to Spielberger (1980) the Test Anxiety Inventory is specially designed to measure the test anxiety of high school and college students. It contains three subscales: Test Anxiety-Total (TAI-T), Test Anxiety-Worry (TAI-W), and Test Anxiety-Emotionality (TAI-E). Eight items of Test Anxiety Inventory measure the TAI-W, eight items measure TAI-E and the remaining four for measuring TAI-T. Test Anxiety Inventory is a 4-point Likert type scale and the students have to respond to the four options: (1) Almost Never, (2) Sometimes, (3) Often and (4) Almost Always. The reliability values of the alpha coefficient for subscales of the original version of Test Anxiety Inventory were: 0.96 for TAI-T, 0.91 for TAI-W and 0.91 for TAI-E (Spielberger 1980). The Mathematics Achievement Test was constructed by the researchers with 20 objective test items. The MAT was used to measure students' academic performance in Mathematics. The MAT was tested for reliability using Cronbach Alpha after a trial test was carried out. The reliability value of 0.795 indicated that the MAT was internally consistent for measurement. In collecting data for the study, the sample of respondents was systematically divided into control and treatment groups, with each group having 164 students. The control group was taught a topic in Mathematics using the traditional method of teaching, while in the treatment group, the same topic was taught using Poll Everywhere E-learning platform. At the end of the exercise, the Test Anxiety Inventory (TAI) and Mathematics Achievement Test (MAT) were administered to the students in the control using Paper and Pencil Approach (PPA). The same instruments TAI and MAT were administered to the treatment group using the Poll Everywhere E-learning platform. Participants in both groups responded to the items accordingly and at the end of the exercise, all the administered copies of the instruments were retrieved and collated. The collated data were analysed using descriptive statistics, while the null hypotheses were all tested using independent t-tests (for $\mathrm{Ho}_{1}$ and $\mathrm{Ho}_{2}$ ) and simple linear regression (for $\mathrm{Ho}_{3}$ ). The results of the analyses are presented in the following section.

\section{RESULTS}

\subsection{Hypothesis One}

Poll Everywhere E-learning platform has no significant effect on students' test anxiety. This null hypothesis was tested using independent t-test based on the test anxiety data collected from the treatment and control groups. The result of the analysis is presented in Table 1. 
Table-1. Independent t-test results summary showing the effect of Poll Everywhere E-learning platform and students' test anxiety.

\begin{tabular}{ccccccc}
\hline Variables & Groups & N & Mean & SD & t-Cal. & Sig. \\
\hline Test anxiety & Treatment & 164 & 30.09 & 8.155 & & \\
& & & & & $20.170^{*}$ & .000 \\
\hline
\end{tabular}

Note: *Significant at the .01 level; $\mathrm{Df}=326 ;$ Mean difference $=26.628$

From the results presented in Table 1 it was discovered that students in the treatment group achieved lower test anxiety means than their counterparts in the control group. This suggests that test anxiety was higher in students that were taught using traditional teaching methods than in those taught using the Poll Everywhere Elearning platform with a mean difference of 26.628. The p-value of .000 is less than the .05 alpha level at 326 degrees of freedom. Based on this result, the null hypothesis was rejected while the alternate hypothesis was retained. By implication, Poll Everywhere E-learning platform has a significant effect on students' test anxiety.

\subsection{Hypothesis Two}

Poll Everywhere E-learning platform has no significant effect on students' academic performance in Mathematics. This hypothesis was tested using independent t-test based on students' performance in the MAT from both the treatment and control groups. The result of the analysis is presented in Table 2.

Table-2. Independent t-test results summary showing the effect of Poll Everywhere E-learning platform and students' academic performance in Mathematics.

\begin{tabular}{|c|c|c|c|c|c|c|}
\hline Variable & Groups & $\mathbf{N}$ & Mean & SD & t-Cal. & Sig. \\
\hline \multirow[t]{3}{*}{ Academic performance in mathematics } & Treatment & 164 & 14.58 & 3.496 & & \\
\hline & & & & & $15.304^{*}$ & .000 \\
\hline & Control & 164 & 8.02 & 4.233 & & \\
\hline
\end{tabular}

The results as presented in Table indicates that the mean of students' academic performance in Mathematics was higher in the treatment group than in the control group. This suggests that students taught using the Poll Everywhere E-learning platform performed higher in the Mathematics Achievement Test (MAT) than those taught using the traditional teaching methods. A cursory look at the p-value of .ooo shows that it is less than the alpha level of .05 at 326 degrees of freedom. Based on this result, the null hypothesis was rejected implying that Poll Everywhere E-learning platform has a significant effect on students' academic performance in Mathematics.

\subsection{Hypothesis Three}

There is no significant relationship between students' test anxiety and their academic performance in Mathematics. In this hypothesis, the test anxiety scores were correlated with the scores from the MAT using simple linear regression analysis. The result of the analysis is presented in Table 3.

\begin{tabular}{|c|c|c|c|c|c|}
\hline $\mathbf{R}$ & $\mathbf{R}^{2}$ & & Adj. $\mathbf{R}^{2}$ & & SE \\
\hline $.561^{\mathrm{a}}$ & .315 & & .313 & & 4.211 \\
\hline Model & $\mathrm{SS}$ & Df & MS & $\mathrm{F}$ & Sig. \\
\hline Regression & 2660.687 & 1 & 2660.687 & 150.014 & $.000^{b}$ \\
\hline Residual & 5782.032 & 326 & 17.736 & & \\
\hline Total & 8442.720 & 327 & & & \\
\hline
\end{tabular}

Note: $\mathrm{B}=-.159 ; \beta=-.561 ; \mathrm{t}=-12.248 ; \mathrm{p}<.05$ 
The results presented in Table 3 disclosed that there is a moderate relationship $(\mathrm{R}=.561)$ between students' test anxiety and their academic performance in Mathematics. The adjusted R square value of .313 suggests that $31.3 \%$ of the total variance in students' academic performance in Mathematics is explained by their test anxiety, with the remaining $68.7 \%$ explained by other extraneous variables. A close look at the p-value shows that it is less than the alpha level of .05 at 1 and 326 degrees of freedom. Based on this result, the null hypothesis was rejected while the alternate hypothesis was retained. This implies that there is a significant relationship between students' test anxiety and their academic performance in Mathematics. The Beta weight of -.561 indicates that there is a significant inverse relationship between students' test anxiety and their academic performance in Mathematics such that a unit increase in the standard deviation of students' test anxiety will lead to a 0.561 decrease in their academic performance in Mathematics, other things being equal.

\section{DISCUSSION}

The first finding of this study showed that Poll Everywhere E-learning platform has a significant effect on students' test anxiety. As test anxiety was lower when students taught with the Poll Everywhere eLearning took the test than those who were taught using the traditional approach. This finding may have appeared this way since users of Poll Everywhere platform are remote from others as well as their teachers. Thus, it reduces the fear usually imposed by their colleagues who could express their fears for the test, making listening colleagues to be afraid too. Students self-confidence may also be boosted if they are aware that there is no supervisor around them and no one to talk to, as they sit in the comfort of their homes or a convenient location to take the test. This finding corroborates the results of earlier studies (Alkhalaf et al., 2012; Bauk, 2015; Harandi, 2015) which all indicated that eLearning has a significant relationship to students' test anxiety. The results of Yazdi and Zandkarimi (2013) showed that e-learning in present site with teachers Teleworking and parent's virtual presence were more effective than the control group.

The second finding of this study indicated that Poll Everywhere eLearning platform has a significant effect on students' academic performance in Mathematics. Students taught using the Poll Everywhere E-learning platform performed higher in the Mathematics Achievement Test (MAT) than those taught using the traditional teaching methods. This finding is unsurprising since it has earlier been established that the use of Poll Everywhere eLearning platform reduces test anxiety and boosts self-confidence. Such reduction and a boost in test anxiety and self-confidence respectively could be the reason why Poll Everywhere platform improves students' academic performance.

This finding aligns with the results of Zare et al. (2016) which revealed that students in the experimental group demonstrated statistically significant higher scores on the measured variables, knowledge, and creativity. The study concluded that e-learning is effective for knowledge and creativity acquisitions among students and recommended that greater e-learning opportunities should be provided for wider audiences. Similarly, Tossy (2017) found that student confidence in e-learning systems have a positive significant relationship with students' achievement. Thabet and Kalyankar (2014) showed that there is a significant increase in gain in achievement, the EL has achieved efficiency greater than traditional learning in (Remembering, understanding, application) skills.

Furthermore, Mutendwahothe (2013) provided evidence that e-Learning has a significant influence on the performance of students, as student-teachers taught using eLearning consistently performed better than studentteachers taught using the traditional method. Another study also showed that students' confidence in e-learning systems have a positive significant relationship with their achievement (Kisanjara et al., 2017). 
It was established through the third finding of this study that there is a moderate negative and significant relationship between students' test anxiety and their academic performance in Mathematics. With test anxiety contributing $31.3 \%$ to the total variance in students' academic performance in Mathematics. The finding further suggested that a unit increase in the standard deviation of students' test anxiety will lead to a 0.561 decrease in their academic performance in Mathematics, other things being equal. This finding is in line with the results of earlier studies (Owan, 2012; Shuaibu et al., 2017; Effiom and Bassey, 2018; Owan et al., 2019) which showed respectively that students test anxiety affects their academic performance. In line with this finding, the results of Hanem (2016) indicated that there is a high statistically inverse correlation between total test anxiety and grade point average $(\mathrm{P}<.01)$. Another study showed that there is a significant correlation $(\mathrm{r}=-0.23, \mathrm{p}=.000)$ between test anxiety and academic achievement among adolescents (Yousefi et al., 2010). Owan et al. (2019) also discovered that there is an inverse significant relationship $(\mathrm{r}=-339, \mathrm{p}<0.05)$ between students' tests anxiety and performance in mathematics.

\section{CONCLUSION}

Based on the findings of this study, it was concluded that Poll Everywhere eLearning platform could be used for the effective teaching and examination of learners in Mathematics and other behavioural sciences. Poll Everywhere platform reduces students' test anxiety levels and improves students' academic performance in Mathematics. It was also concluded generally that there is an inverse relationship between students' test anxiety and their academic performance in Mathematics.

\section{RECOMMENDATIONS}

Based on the conclusion of this study, the following recommendations were made:

i. Poll Everywhere eLearning platform should be adopted by every Nigerian university in the teaching and instruction of learners for improved understanding and better academic performance in Mathematics

ii. The government, as well as university management, should also ensure that there are open wireless networks that will not require any form of subscription from lecturers or students before assessing internet facilities in the school. This will enable the staff and students to use the Poll Everywhere eLearning platform uninterruptedly.

iii. Teachers should be retrained on how to use the Poll Everywhere mobile app or website. This can be done through seminars or workshops to enable them to become effective users of the eLearning platform.

iv. As an eLearning platform, Poll Everywhere application or website should be used as a channel for testing students' abilities and during examinations to reduce students' test anxiety and consequently, their academic achievement.

v. Experts in psychology, as well as counselling experts, should be employed in adequate numbers to assist in reducing students' test anxiety before the commencement of any examination. This will assist in making such learners prepared for examinations and will further improve the level of their academic performance.

\section{REFERENCES}

Adu, E., R. Tadu and I. Eze, 2012. Teachers' self-efficacy as correlates of secondary school students' academic achievement in Southwestern Nigeria. Discovery, 2(4): 8-16.

Ali, S., Z. Haider, F. Munir, H. Khan and A. Ahmed, 2013. Factors contributing to the students academic performance: A case study of islamia university sub-campus. American Journal of Educational Research, 1(8): $283-289$. 
Alkhalaf, S., S. Drew and T. Alhussain, 2012. Assessing the impact of e-learning systems on learners: A survey study in the KSA. Procedia-Social and Behavioral Sciences, 47: 98-104.Available at: https://doi.org/10.1016/j.sbspro.2012.06.620.

Aripin, R., Z. Mahmood, R. Rohaizad, U. Yeop and M. Anuar, 2008. Students' learning styles and academic performance. 22nd Annual SAS Malaysia Forum, 15th July 2008, Kuala Lumpur Convention Center, Kuala Lumpur, Malaysia.

Arop, F.O., J.N. Agunwa and V.J. Owan, 2019. Tertiary students' social media management attitudes and academic performance in Cross River State. British International Journal of Education and Social Sciences, 6(3): 48-52.

Bassey, B.A., V.J. Owan and J.N. Agunwa, 2019. Quality assurance practices and students' performance evaluation in universities of South-South Nigeria: A structural equation modelling approach. British Journal of Psychology Research, 7(3): 1-13.

Bauk, S.I., 2015. Assessing students' perception of e-learning in blended environment: An experimental study. Procedia-Social and Behavioral Sciences, 191: 323-329.Available at: https://doi.org/10.1016/j.sbspro.2015.04.393.

Bhatta, K.R., S. Subba and S. Bhandary, 2018. Test anxiety: Prevalence and correlates. International Journal of Current Research and Academic Review, 6(8): 75-82.

Coldwell, J., A. Craig, T. Paterson and J. Mustard, 2008. Online students: Relationships between participation, demographics and academic performance. The Electronic Journal of e-Learning, 6(1): $19-30$.

Effiom, B.E. and B. Bassey, 2018. Test anxiety, self esteem and academic performance among secondary school students in Cross River State, Nigeria. International Journal of Education and Evaluation, 4(9): 18-27.

Ehiane, O.S., 2014. Discipline and academic performance (A study of selected secondary schools in Lagos, Nigeria). International Journal of Academic Research in Progressive Education and Development, 3(1): 181-194.Available at: https://doi.org/10.6007/ijarped/v3-i1/758.

Ganyaupfu, E.M., 2013. Teaching methods and students' academic performance. International Journal of Humanities and Social Science Invention, 2(9): 29-35.

Haist, S.A., J.F. Wilson, C.L. Elam, A.V. Blue and S.E. Fosson, 2000. The effect of gender and age on medical school performance: An important interaction. Advances in Health sciences Education, 5(3): 197-205.

Hanem, A.A.A., 2016. Exploring the relationship between test anxiety and academic achievement among female nursing students at Zagazig University. IOSR Journal of Nursing and Health Science, 5(5): $43-48$.

Harandi, S.R., 2015. Effects of e-learning on students' motivation. Paper Presented at the 3rd International Conference on Leadership, Technology and Innovation Management. Procedia - Social and Behavioral Sciences, 181: 423 430.Available at: 10.1016/j.sbspro.2015.04.905.

Heinesen, E., 2010. Estimating class-size effects using within-school variation in subject-specific classes. The Economic Journal, 120(545): 737-760.Available at: https://doi.org/10.1111/j.1468-0297.2009.02301.x.

Holt, S.B. and S. Gershenson, 2015. The impact of teacher demographic representation on student attendance and suspensions. Working Paper (No. 9554). Iza.

Kisanjara, S.B., T.M. Tossy, A.S. Sife and M. S.S., 2017. An integrated model for measuring the impacts of e-learning on students' achievement in developing countries. International Journal of Education and Development using Information and Communication Technology, 13(3): 109-127.

Lagoke, B.A., M.D. Komolafe, N.A. Ige and M.A. Oladejo, 2010. Disability status and academic performance in a Nigerian university: Instructional implications for inclusive distance education practice. European Journal of Social Sciences, 17(3): 303-315.

Mlambo, V., 2011. An analysis of some factors affecting student academic performance in an introductory biochemistry course at the University of the West Indies. Carribean Teaching Scholar, 1(2): 79-92.

Mutendwahothe, L.W., 2013. E-learning's impact on the academic performance of student-teachers: A curriculum lens. Mediterranean Journal of Social Sciences, 4(14): 695-703. 
Offem, O.O., F.O. Arop and V.J. Owan, 2019. Students' perception towards management of discipline and their academic performance in Cross River State. Global Journal of Academic Research (GJAR), 3(1): 34-40.

Owan, V.J., 2012. Some causes of poor performance of pupils in primary school Mathematics. A case study in Akamkpa Local Government Area of Cross River State, Nigeria. (Cross River State College of Education, Akamkpa). Available from https://goo.gl/NTTxq.

Owan, V.J. and S.O. Ekaette, 2019. Students' personnel management and academic effectiveness of secondary school students in Calabar Education Zone of Cross River State, Nigeria. International Journal of Psychological and Brain Sciences, 4(2): 13-19.Available at: https://doi.org/10.11648/j.ijpbs.20190402.12.

Owan, V.J. and M.B. Ekpe, 2019. Disciplinary management in public primary schools and teachers' job effectiveness in yakurr local government area, cross river state, nigeria. World Journal of Vocational Education and Training, 1(1): 1-10.

Owan, V.J., E. Etudor-Eyo and U.U. Esuong, 2019. Administration of punishment, students' test anxiety, and performance in Mathematics in secondary schools of Cross River State, Nigeria. International Journal of Academic Research in Business and Social Sciences, 9(6): 415-430.

Owan, V.J., B.I. Nwannunu and E.C. Madukwe, 2018. Problems of school management and students' academic performance in secondary schools in Calabar Education Zone, Cross River State, Nigeria. International Journal of Research and Innovation in Social Science (IJRISS), 2(10): 120-127.

Owan, V.J. and A.I. Robert, 2019. Analysis of the utilization of social media platforms and university students' attitudes towards academic activities in Cross River State, Nigeria. Prestige Journal of Education, 2(1): 1-13.

Shuaibu, M., H. Surajo and M.A. Muhammadi, 2017. Effects of examination anxiety on university students' academic performance in Northwest University, Kano, Nigeria. European Journal of Education Studies, 3(5): 796 - 807.

Spielberger, C.D., 1980. Test anxiety inventory: Preliminary professional manual. Palo Alto, CA: Consulting Psychologists Press.

Tatlah, I.A., M.Z. Iqbal, M. Amin and U. Quraishi, 2014. Effect of leadership behaviour of principals on students' academic achievement at secondary level: A comparison of the leaders and teachers' perceptions. Journal of Research and Reflections in Education, 8(1): 1-12.

Thabet, T.S.A. and N.V. Kalyankar, 2014. The effect of E-learning approach on sudents' achievement in Fraction Math Course Level 5 at Yemen's Public Primary School. Global Journal of Computer Science and Technology: E Network, Web \& Security, 14(2): 45-51.

Tossy, T., 2017. Measuring the impacts of e-learning on students' achievement in learning process: An experience from tanzanian public universities. The Online Journal of Distance Education and e-Learning, 5(2): 61-68.

Yazdi, S.M. and G. Zandkarimi, 2013. The impact of e-learning on some psychological dimensions and academic achievement. International Journal of Education and Learning, 2(2): 40-58.Available at: https://doi.org/10.14257/ijel.2013.2.2.05.

Yousefi, F., M.A. Talib, M.B. Mansor and R.B. Juhari, 2010. The relationship between test-anxiety and academic achievement among iranian adolescents. Asian Social Science, 6(5): 100-105.Available at: https://doi.org/10.5539/ass.v6n5p100.

Zare, M., R. Sarikhani, M. Salari and V. Mansouri, 2016. The impact of e-learning on university students' academic achievement and creativity. Journal of Technical Education and Training, 8(1): 25-33.

Online Science Publishing is not responsible or answerable for any loss, damage or liability, etc. caused in relation to/arising out of the use of the content. Any queries should be directed to the corresponding author of the article. 